\title{
A SINCRETIZAÇÃO REGULATÓRIA ENTRE A FEDERAÇÃO DE COOPERATIVAS DE ENERGIAS RENOVÁVEIS COM A REGULAÇÃO REGIONAL DA UNIÃO EUROPEIA
}

\author{
Othon Pantoja Oliveira de Azevedo ${ }^{1}$
}

\section{Resumo:}

A Diretiva 2009/28/CE (DER/2009) que regula respeito das energias renováveis da União Europeia foi um passo necessário para tentar concretizar as abstrações estabelecidas pelo Direito Internacional Público em relação às mudanças climáticas. No entanto, a DER/2009 por ser uma regulação que estabeleceu meta de consumo final de $20 \%$ por fontes renováveis de energia, não deu ensejo a autorregulação estabelecida pela Federação de Cooperativas de Energias Renováveis. Desse modo o pluralismo jurídico advindo da sociedade civil possibilitou sincretismo da autorregulação das cooperativas para com o a estrutura regulatória da UE a fim de complementar as lacunas deixadas pela regulação.

Palavras-chave: Energias renováveis; mudanças climáticas; Direito Internacional Público; cooperativas; pluralismo jurídico

\section{A REGULATORY SINCRETIZATION BETWEEN A FEDERATION OF RENEWABLE ENERGY COOPERATIVES WITH REGIONAL REGULATION OF THE EUROPEAN UNION}

\section{Abstract:}

The Directive 2009/28/EC, which regulates respect for renewable energies in the European Union, was a necessary step in trying to achieve the abstractions established by international public law in relation to climate change. However, DER / 2009, as a regulation that established a final consumption target of $20 \%$ for renewable energy sources, did not give rise to the self-regulation established by the Federation of Cooperatives of Renewable Energies. In this way, the legal pluralism arising from civil society has allowed syncretism of the selfregulation of cooperatives towards the EU regulatory structure in order to complement the gaps left by regulation.

Keywords: Renewable energy; climate changes; Public International Law; cooperatives; legal pluralism

\section{INTRODUÇÃO}

A governança tradicional é formada pelo entendimento de que o Estado e as Organizações Internacionais possuem o monopólio da produção normativa (KINGSBURY; CAISINI, 2009). Partindo desse pressuposto, de acordo com a governança tradicional, não há

\footnotetext{
${ }^{1}$ É Mestre em Direito pelo programa de pós-graduação Stricto Sensu do Centro Universitário de Brasília UNICEUB, na linha de pesquisa Políticas Públicas e Desenvolvimento Econômico, sob o tema "A Governança Global das Energias Renováveis. Utiliza como teoria o Direito Administrativo Global para ampliar o alcance do Direito Internacional Ambiental. E-mail: othon.pantoja@gmail.com.
} 
uma divisão entre direito interno e direito internacional e estes estão consolidados de forma unitária (KELSEN, 1998, 230-231).

Por outro lado, a globalização tem modificado as estruturas de governança bem como transformado o modo de pensar e debater o direito, haja vista que este tem se desenhado de maneira transfronteiriça e de forma fragmentada. Tal fragmentação pode ser atribuída ao excesso de especialização que as diferentes vertentes do Direito Internacional Público acrescentaram, bem como da contribuição regulatória por fontes não estatais e/ou híbridas (NASSER, 2015).

O que se pode explicar essa nova governança, é a perspectiva empresarial da gestão pública, na medida em que o Estado foi "reprogramado" em nome de uma liberdade maior de se fazer negócios, e assim reduzindo a prestação de serviços sociais à mera relação de consumo (DARDOT; LAVAL, 2016, p. 274). Nesse sentido, será feita uma crítica a essa nova governança que se integra a um capitalismo globalizado impulsionado por uma razão neoliberal, e por consequência, criam barreiras para a democratização das tomadas de decisões.

A escolha pelo estudo de caso da União Europeia (doravante, UE), se justifica em razão do seu grau de aperfeiçoamento administrativo, haja vista que possui estruturas dos três poderes em sua formação política. Além disso, em virtude de o seu corpo administrativo possuir uma estrutura complexa, outras formas de legislar a fim de alcançar objetivos estabelecidos pelos Tratados, que são: Regulamentos, Diretivas, Decisões, Recomendações e Pareceres. Dentre as diferentes formas de regulação, como recorte temático, optou-se como estudo de caso as diretivas que tratam sobre as fontes renováveis de energia. Trata-se de um ato administrativo, que busca trazer padrões regulatórios a todos os membros da UE.

Todavia, cabe a cada estado membro individualmente legislar internamente a fim de alcançar as regras estabelecidas no cerne diretiva. As diretivas possuem o condão de regular os mercados com o intuito de criar regras gerais intercomunitárias para facilitar as transações econômicas entre os estados-membros e dependendo do caso, também com terceiros.

Desta forma, como resultado dessa "nova ordem mundial" (SLAUGHTER, 2004), a UE pode ser considerada como um laboratório do Direito Global ${ }^{2}$ (FRYDMAN, 2012, p. 05).

\footnotetext{
${ }^{2}$ Entende-se por Direito Global o estudo dos efeitos da globalização em uma sociedade global, através de suas relações transnacionais por meio de redes. Tais relações podem ser diversas: através de instrumentos jurídicos estatais tradicionais, por meio de regulações de mercado com efeitos jurídicos; mediante decisões administrativas de órgãos internacionais ou órgãos intergovernamentais; por intermédio do engajamento social
} 
Tal panorama se dá pela interação entre o direito administrativo da UE com o Direito Administrativo Global $(\mathrm{DAG})^{3}$, sendo possível investigar o caminho entre o Direito Internacional Público (DIP) e a experiência administrativa dos Estados (CHITI, 2011, p. 02), por meio de uma intersecção entre Direito Internacional Público, DAG e UE (MENDES, 2011, p. 117-120).

No contexto da UE, não se pode explicar a interação entre o DIP e o Direito da UE como uma mera internalização. Pois ela se deu por meio do processo de integração regional (DIZ, JÚNIOR, 2015, p. 138-158) mediante uma abordagem específica a respeito das Energias Renováveis. A regulação energética buscou preencher os espaços deixados pelo DIP sobre o tema ao mesmo tempo em que criou mecanismos administrativos estabelecidos pela governança climática internacional (FRYDMAN, 2012).

Dessa forma, a Diretiva 2009/28/CE possui como meta de desempenho, com o estabelecimento de $20 \%$ de consumo final a partir de fontes renováveis de energia até o ano de 2020 (adiante, DER/2009). No entanto, apesar de as metas estarem dentro de sua previsibilidade, não há uma demonstração de o resultado previsto ter sido em consequência da regulação.

Apesar de ter um sistema de medição aprimorado das metas estabelecidas, a sua accountability não consegue demonstrar toda a extensão da cadeia produtiva de ER, como por exemplo as cooperativas de ER. As Cooperativas de ER (Renewable Energy Cooperatives RECS), são frutos de autorganização social de cidadãos, que inicialmente se deu de forma fragmentada e dispersas na segunda metade dos anos 2000, e que posteriormente se associaram mediante uma Federação de ER (Renewable Energies Cooperatives - REscoop).

Ademais, a REscoop criou uma estrutura regulatória que dialoga com a estrutura de governança da UE, haja vista que a mesma ocorreu mediante o pluralismo jurídico, que não se insere num contexto não hierárquico das normas. Tal panorama criou redes de iniciativas regulatórias multiníveis, que se integra a um Direito Global por serem práticas locais que acontecem ao longo de toda UE que influenciam no âmbito global.

com impactos em políticas públicas etc. Pode-se dizer que existem diferentes abordagens do Direito Global, por diversos autores, que usam, por sua vez, diferentes metodologias.

${ }^{3}$ O DAG é ser uma ferramenta de análise do direito por meio de mecanismos do direito administrativo local a nível global. Por exemplo, uma tomada de decisão de uma autoridade local para a elaboração de uma política pública pode ter efeito transfronteiriço. 
Portanto, será utilizado o método dedutivo através tanto da revisão bibliográfica sobre o tema, quanto da observação das normas internacionais que tratam sobre mudanças climáticas, bem como o seu diálogo com as diretivas estabelecidas pela União Europeia.

Destarte, o artigo será dividido em três partes: 1) A União Europeia como laboratório do Direito Global a partir da integração regional; 2) Os limites da efetividade regulatória de ER da UE; 3) A emergência do pluralismo jurídico a partir da dialética entre a Federação de Cooperativas de ER para com a estrutura regulatória da UE.

\section{A UNIÃO EUROPEIA COMO LABORATÓRIO DO DIREITO GLOBAL A PARTIR DA INTEGRAÇÃO REGIONAL}

A UE estabeleceu uma estrutura regulatória energética na medida em que o Direito Internacional Ambiental tem sobre ela grande influência, assim como sobre os seus países membros, principalmente o arcabouço jurídico constituído a partir da Convenção- Quadro das Nações Unidas sobre as Mudanças do Clima (do inglês United Nations Framework Convention on Climate Change - UNFCCC em 1992 (CHITI; MARATELLA, 2011, p. 02). Para tanto, necessitar-se-á explicar a linha temporal acerca da regulação ambiental que ocorreu sob influência da regulação internacional a respeito das mudanças climáticas.

Anote-se, que as primeiras diretivas, promulgadas entre 1970 (Diretiva 77/220/CEE), 1989 (89/458/CEE) e 1991 (Diretiva 91/441/CEE), a regulação se restringia as emissões de poluentes de veículos automotivos, mas sem haver relação com a norma internacional ambiental. Já a diretiva de 1994 (94/12/CE), apesar de estar atrelada a diretiva de 1970, passou a ter a preocupação de atender a regulação internacional estabelecida pela UNFCCC em reduzir as emissões antrópicas de GEE, mas ainda na parte das considerações da norma europeia. No entanto, tal situação não se repetiu com as diretivas de 1996 (Diretiva 96/69/CE) e 1998 (Diretiva 98/69/CE), sem mencionar em atender as regras da UNFCCC.

A partir da Diretiva 2001/77/EC (revogada em 2009), foi elaborada no sentido de dar diretrizes gerais aos países membros para a promoção de energia elétrica por meio de fontes renováveis. Seu objetivo era a promoção do desenvolvimento sustentável, visando atender às medidas necessárias estabelecidas pela UNFCCC, pelo Protocolo de Kyoto e por outras medidas posteriores relativas ao tema no âmbito global. 
É importante esclarecer, que foi a partir de 2001 que a regulação passou a ter a pretensão de seguir as metas de redução de gases de efeito estufa em busca da mitigação das mudanças climáticas. A UE, como uma região de integração econômica, incentivou políticas públicas no sentido de fomentar a mercantilização da energia através de fontes renováveis de energia que não emitem gases de efeito estufa. Nesse sentido, a UE atrelou a legislação europeia em relação às normas ambientais internacionais (BRADBROOK, 2008, p. 109).

O objetivo da Diretiva 2009/28/CE é que cada estado membro individualmente contribua para com a cota global $20 \%$ de energia oriunda de fontes renováveis até 2020, sendo $10 \%$ desse total derivada dos transportes. Também teve como objetivo a elaboração de um plano de ação definindo um objetivo nacional. O plano de ação nacional deve ser aprovado por cada estado membro, sendo relacionado com outras medidas referentes à eficiência energética no consumo final de energia e com os objetivos globais, nacionais, regionais, em cooperação com as autoridades locais. Além disso, é possível comprar e vender os excedentes de outros estados membros da UE e até mesmo de outros países não-membros para alcançar as metas.

Diante desse cenário, foi criado um roteiro com as metas de crescimento do consumo final de energias renováveis em 2050 e de redução de Gases de Efeito Estufa (GEE) de 80\% a 95\% inferior aos níveis de 1990. Após o Acordo de Paris em 2015, documento resultante da Vigésima Primeira Conferências das Partes ${ }^{4}$, a UE reformulou as suas estratégias de baixo carbono até meados do século, com as edições do novo pacote climático mediante as Diretivas 2018/2001/(ER) e 2018/2002 (Eficiência Energética). Houve modificações para o ano 2030, com as atualizações das metas de reduções e da metodologia, a partir do ano 2021, os Estados não terão metas individuais obrigatórias, mas tão somente meta global à UE. Por se tratar de uma diretiva que terá validade a partir de 2021, não será tratada no presente artigo.

Como exposto acima, a estrutura regulatória concernente à ER tem como mote principal, a tentativa gerar incentivos econômicos para o crescimento do mercado, como fruto de uma nova governança globalizada (DARDOT; LAVAL, 2016, p. 271-288), de viés neoliberal voltada para a mercantilização da energia. Nesta seara, no sentido de a indústria de produção de insumos para os modos de produção de ER, levar certo tempo até alcançar a produção de escala a ponto de atingir um preço economicamente viável ao consumo final. Tal

\footnotetext{
${ }^{4}$ Encontro anual realizado entre os países membros da UNFCCC para tratar questões pertinentes às mudanças climáticas.
} 
panorama, leva a uma corrida para baixo com o intuito de conseguir concorrer com fontes energéticas tradicionais, tais como o carvão e energia nuclear.

Desta forma, é mister para a regulação do mercado de energias renováveis o trabalho de institucionalização e estabilização de numerosas regras para assegurar o seu bom funcionamento (FRYDMAN, 2012, p. 15). A Diretiva de Energias Renováveis (DER/2009), foi pensada para buscar a independência do mercado, impulsionar seu bom funcionamento e estimular a concorrência. Por outro lado, a falha de sua regulação obstaria a efetiva implementação ante a ausência dos investimentos privados (LEAL-ARCAS; MINAS, 2016, p. 37).

Nesse diapasão, para garantir a capacidade de investimento privado, a DER/2009 prevê a capacidade de comunicação entre os estados membros e não-membros, na ocasião de sua publicação, houve convergência regulatória tanto com o Protocolo de Kyoto, quanto ao Acordo de Paris. Os Estados Membros podem transferir a produção de ER entre eles, por meio de mecanismos de cooperação para alcançarem as suas metas obrigatórias, entre si, mas também entre outros países. Da mesma maneira é factível aos estados membros a transferência estatística de uma quantidade de ER. Com isso, abre-se a possibilidade para a participação de operadores privados quando houver cooperação entre dois Estados Membros de projetos conjuntos de ER.

Desta forma, as regras nacionais devem prever a autorização, certificação e licenciamento de produtos concernentes às energias renováveis, tais como os projetos relacionados às transmissões e redes de distribuição, com transparência e accountability do planejamento e da construção. Devem ser tomadas medidas para desenvolver redes de transmissões com segurança e tecnologia, incluindo a interligação entre Estados Membros e outros terceiros Estados.

Portanto, a DER/2009 possibilitou a criação de uma infraestrutura regulatória e o desenvolvimento de um mercado, partindo da norma regional e chegando a níveis de detalhes específicos do nicho do negócio por fontes renováveis de energia. Pode-se afirmar que a governança ultrapassa o regionalismo proposto pela DER/2009 ao autorizar a negociação com terceiros países em relação a UE. Assim sendo, tais interações são restritas ao campo econômico, uma vez que abre possibilidades para investimentos por meio de operadores privados. Isto é, dá ensejo à pesquisa, a inovação e as transferências tecnológicas, sem 
garantir a democracia energética e a participação dos cidadãos, bem como a proteção ambiental se dá de forma meramente alegórica (LEAL-ARCAS; MINAS, 2016, p. 39).

Pelos motivos de a DER/2009 se ater somente para com a abertura de novos mercados e a possibilidades de gerar lucros, questiona-se a implementação da DER, tendo em vista os riscos ao funcionamento dos mercados pela flutuação dos investimentos privados. Atribui-se a esses riscos, em razão do tratamento dado a diferentes estados membros, que por sua vez infringem metas de redução de GEE ao modificarem seus próprios esquemas internos.

Dessa forma, a utilização de políticas neoliberais cooptou as medidas que deveriam ser primordialmente ambientais, e assim levando à morosidade em ampliar as redes de transmissão e à criação de infraestrutura. Em razão disso, deixou os operadores de ER à mercê da competitividade de um livre mercado outras fontes tradicionais de energia, que possuem vantagens competitivas por infraestrutura e financiamento (LEAL-ARCAS; MINAS, 2016, p. 40-41).

A presente seção abordou a intersecção entre o Direito Internacional Público (DIP) e o Direito da UE, sob o viés ambiental, em que se busca uma transição para a economia verde, cujo padrão regulatório europeu foi influenciado pela norma internacional. Portanto, o processo de influência do DIP para com a UE, possibilitou a elaboração de políticas públicas dentro do bloco comunitário para a transição às ER.

Diante do exposto, a regulação europeia se deu pelo processo de integração regional, por meio da análise de sua regulação que levou à constatação da existência de lacunas a serem preenchidas. Tais lacunas serão observadas pela análise da efetividade da regulação dentro do espaço administrativo da UE, demonstraremos as suas limitações na próxima seção do artigo.

\section{OS LIMITES DA EFETIVIDADE DA DER/2009 DA UNIÃO EUROPEIA PARA ALCANÇAR A META DE 20\% DE CONSUMO FINAL DE ENERGIA POR FONTES RENOVÁVEIS PARA O ANO DE 2020}

A validade da norma jurídica passa pela capacidade dos órgãos executivos de aplicála efetivamente (BARRAUD, 2016, p. 385). Entende-se por órgãos executivos, os órgãos responsáveis pela aplicação da norma. Na presente seção, serão abordadas as possibilidades de diferentes órgãos em sua capacidade de aplicabilidade do Direito.

A efetividade é a maneira pela qual se consegue alcançar os objetivos de uma governança, tratando-se, portanto, da própria implementação da política pública, que pode 
ocorrer mesmo quando não for eficaz. Nesse sentido, será avaliado: se os instrumentos de governança de ER são, de fato, efetivos. Utiliza-se aqui o termo "instrumentos jurídicos" não somente como norma jurídica positivada, mas também como políticas públicas e tomadas de decisões por uma autoridade, seja por meio de um ato administrativo, seja por uma decisão judicial.

$\mathrm{Na}$ seção anterior, abordou-se a respeito do arcabouço regulatório sobre ER e as mudanças climáticas na UE, e de que modo este foi influenciado pela regulação internacional. Agora, será verificada a efetividade da DER/2009, e de que forma ela se pelo uso de critérios utilizados pelo Direito Administrativo Global, para verificação, como accountability, transparência, participação e decisão fundamentada.

Os primeiros pontos analisados serão a accountability e a transparência, ou seja, a forma pela qual a UE e os estados membros prestam conta de suas obrigações a respeito da regulação ambiental e das energias renováveis. A accountability tem o intuito de verificar se há mecanismos de prestações de contas com regras claras, de modo que as partes interessadas possam acompanhar o desempenho da DER/2009 com a transparência necessária dos dados e um acesso facilitado.

Em que se pese a regulação da UE, conhecida por pacote climático (2020 e 2030), ter passado por modificações no final de 2018, será considerada a efetividade da regulação levando em conta os objetivos e as metas elaboradas pelo corpo normativo regional ao longo do tempo. Na infraestrutura 2020, por exemplo, havia a meta do 20/20/20, que era a redução de $20 \%$ de emissões gases de efeito estufa - GEE, 20\% de capacidade, de ER instaladas e 20\% de eficiência energética, sendo avaliada, nesse caso, a efetividade das metas relativas às ER.

A respeito da produção de energia elétrica por meio de fontes renováveis de energia, o órgão responsável por sua accountability é a Agência Europeia do Meio Ambiente (European Environmental Agency - EEA), com uso de indicadores de desempenho. Até que a nova Diretiva (UE) 2018/2001, que regula atualmente as ER, entrasse em vigor, as metas eram vinculativas tanto para a UE, como para os estados membros, e estes deveriam estipular as suas metas individuais por meio de planos de ação nacionais.

Os dados foram cruzados com as metas estabelecidas por meio de gráficos elaborados pela EEA, partindo das seguintes perguntas: Que progressos foram feitos em relação aos $20 \%$ da UE? E em relação à meta de consumo de $20 \%$ energia renovável para 
2020? O progresso deveria ser pensado no sentido dos objetivos de fontes de energia renováveis a nível dos estados membros e considerando os níveis da UE-28.

A medição foi realizada entre os anos de 2005 e 2016, equivalente ao início da vigência do Protocolo de Kyoto até a entrada em vigor do Acordo de Paris, já com novos parâmetros e, portanto, edições de novas Diretivas, a fim de aprimorar a regulação regional de acordo com a internacional, sendo os resultados das novas Diretivas aferidos entre os anos de 2021 e 2030. É importante esclarecer que embora a regulação regional foi criada com base na norma internacional ambiental, esta seguiu o seu curso independentemente da UNFCCC. 
Gráfico 1 - Consumo final de ER bruta compartilhada pelos membros da UE

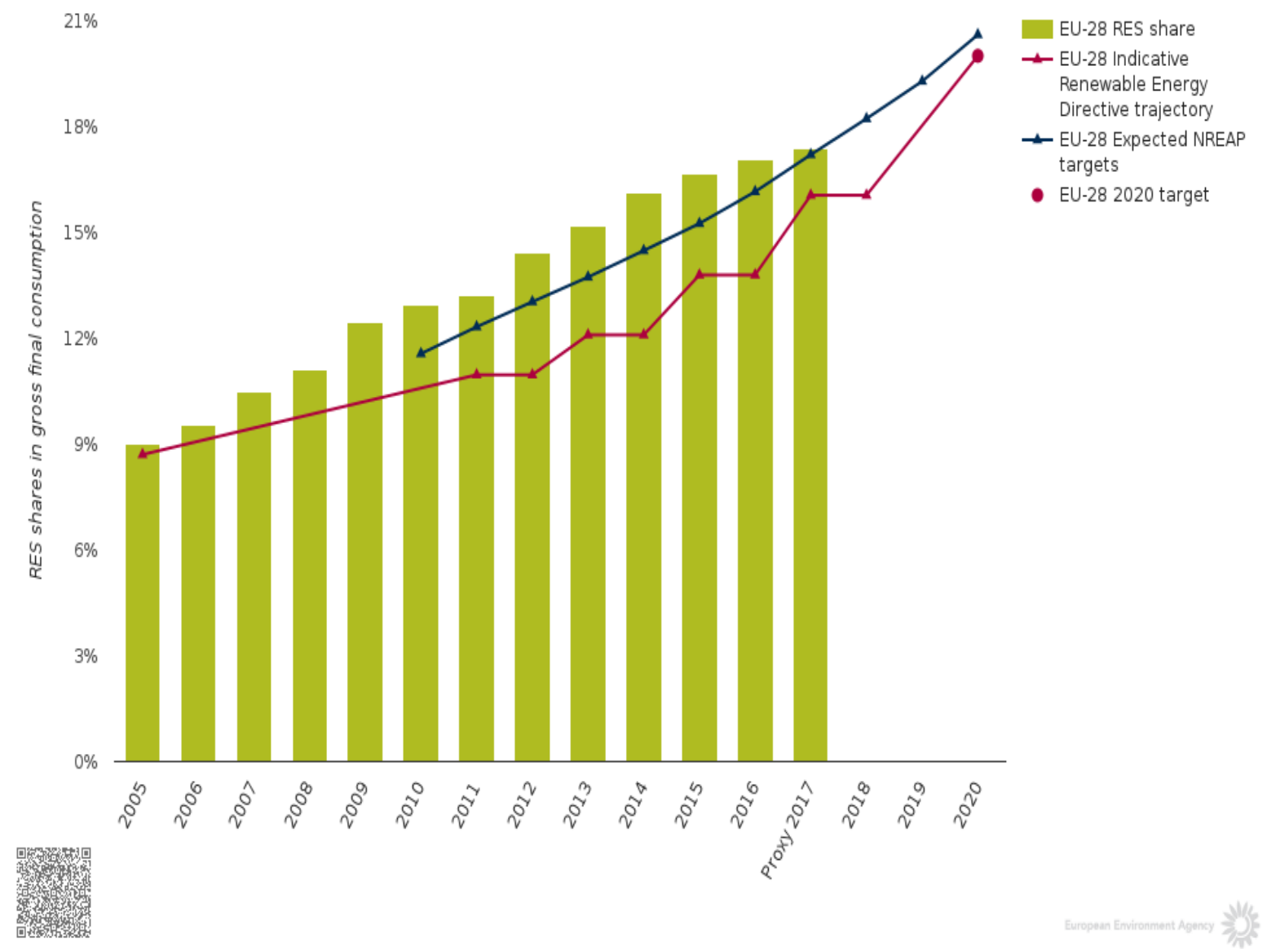

Fonte: Agência Europeia de Meio Ambiente.

Os dados da tabela acima mostram o progresso anual dos números de consumo final de todas as fontes de ER, por tipos de energia elétrica e transporte. Mas em relação aos biocombustíveis, foram inclusos somente os que possuem certificação de sustentabilidade, de acordo com os critérios estabelecidos pela Diretiva de Energias Renováveis (DER/2009). A linha vermelha indica a trajetória estimada pela DER/2009, calculada cumulativamente pelos 28 estados membros da UE, e a linha azul demonstra as estimativas apontadas pelos planos de ação nacionais.

Em termos de desempenho, conseguiu-se ultrapassar a meta prevista para o ano de 2016 (EUROSTAT, 2019) e para as estimativas de 2017, que eram de 17\% e 17,4\%, respectivamente (EEA, 2019). A própria Comissão Europeia é responsável por coletar e divulgar os dados, tendo sido feita a devida prestação de contas (accountability) por meio da EEA, que possui Pontos Focais Nacionais que realizam o monitoramento dos dados por estado membro.

Rev. Brasileira de Direito Internacional | e-ISSN: 2526-0219 | Evento Virtual | v. 6 | n. 1 | p. 57-79 | 
Gráfico 2: Progresso das metas de fontes de energia renováveis por país

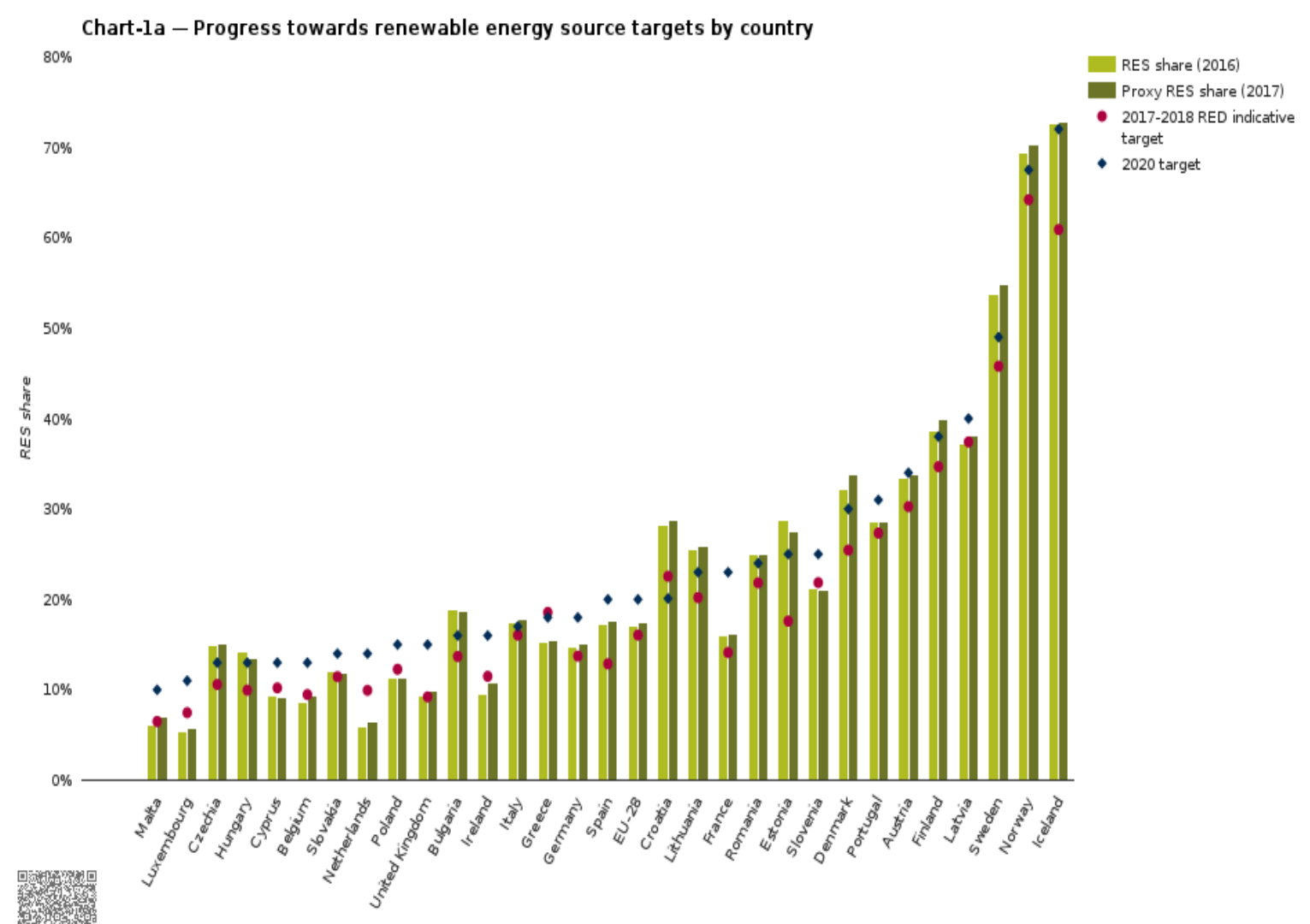

Fonte: Agência Europeia de Meio Ambiente

Assim, pelos dados apresentados, é possível afirmar que as metas estabelecidas pela DER/2009 em relação às metas de consumo final de ER foram atendidas Ao mesmo tempo, houve transparência às partes interessadas na prestação de contas (accountability) e no trabalho do levantamento estatístico realizado pela Eurostat (EUROSTAT, 2019), órgão ligado à Comissão Europeia. Isso significa que os dados estão acessíveis às partes interessadas e que a UE (por meio da Comissão Europeia) se preocupou em deixá-los disponíveis para a consulta do público.

Por outro lado, questiona-se a efetividade da DER/2009, devido aos dados disponíveis não identificarem todo o caminho trilhado, da fonte produtiva, bem como esta foi beneficiada pela diretiva. Por isso, algumas questões ainda estão abertas, entre elas: as partes interessadas criaram empreendimento energéticos com o auxílio da DER/2009? De que forma o direito à participação foi atendido nesse aspecto?

Assim, é verossímil afirmar que os dados fornecidos presumem que as tomadas de decisões e políticas públicas criadas sempre seguiram na direção top down. Dessa forma, ao 
utilizar como método de análise o Direito Administrativo Global para avaliar a efetividade regulatória, é que esta não determinou como os cidadãos poderiam não apenas subsidiar as tomadas de decisões, mas também em dar condições jurídicas e materiais para a geração de ER. Para obter tais respostas, vamos analisar as Cooperativas de Energia Renovável (Renewable Energy Cooperatives - RECs), que foi materialmente a forma encontrada de as partes interessadas participarem da política pública no sentido bottom up (de baixo para cima). Dessa forma, é possível afirmar que as cooperativas, mediante da autorregulação, preenchem as eventuais lacunas deixadas pela DER/2009.

A governança da ER se dá pela interação entre diferentes tipos de atores estatais, sejam nacionais, regionais e até mesmo transnacionais, e ainda com atores não estatais, como ONGs ou organizações baseadas no cidadão, que é o caso das RECs, que serão agora analisadas. A DER/2009, no sentido lato, prevê a participação nos processos de tomadas de decisões públicas e no acesso a informações, mas não fornece condições para a participação pública com o fito de desenvolver empreendimento energéticos de pequena escala ou de informar em que medida pode facilitar o autofinanciamento.

Em razão disso, em que se pese a existência de cooperativas desde os anos 2000, as RECs se auto organizaram por meio de uma associação criada em 2013 (REscoop, 2013), sem fins lucrativos, denominada REScoop, que representa legalmente 1.500 RECs no debate energético no contexto da UE. A REScoop se baseia em sete princípios: 1) adesão voluntária e aberta; 2) controle democrático dos integrantes; 3) participação econômica por meio da propriedade direta; 4) autonomia e independência; 5) educação, treinamento e informação; 6) cooperação entre cooperativas; 7) preocupação com a comunidade (REscoop, 2013).

As RECs se integram extraoficialmente à governança energética europeia, mas fazem parte da transição energética para a democracia de energia e colaboram com os indicadores de desempenho previstos para a regulação estatal. Não obstante, as RECs não surgiram por acaso, mas sim como fruto das constantes crises econômicas e das liberalizações que quebraram os monopólios nas mãos de grandes empresas. Além disso, as tentativas de obterem regulações ao nível europeu foram infrutíferas, mesmo exercendo lobby junto aos membros do Parlamento Europeu, sendo essa a razão do surgimento das federações por meio da REScoop (REscoop, 2015, p. 55).

No entanto, a REScoop não possui estrutura administrativa e financeira para prestar uma accountability de sua rede, além de não ser uma meta pela governança da Federação, mas 
de democratização da produção e consumo de ER. Por esses motivos, não é possível identificar a quantidade de MWh produzidos pelas cooperativas. Tampouco, é possível saber o quanto contribuíram para o consumo bruto final de ER, a fim de contrastar os números com os dados publicados pela Comissão Europeia 312, sem discriminar o que foi de fato fruto da regulação das cooperativas que espontaneamente surgiram para preencher as lacunas da regulação estatal.de facilitar o autofinanciamento.

Os dados que são possíveis de se obter é que existem 1,5 mil RECs na União Europeia, atingindo em torno de 1,5 milhões de cidadãos (REscoop, 2020). Por outro lado, a dificuldade em se prestar contas pode ocorrer por não possuírem uma estrutura para obtenção de dados, não terem acesso à estrutura da UE com esse fim e tampouco condições financeiras favoráveis, tendo em vista que os esforços financeiros são da própria federação. Por esses motivos, não se pode cobrar accountability e transparência das RECs em relação aos aspectos apontados.

Destarte, a presente seção abordou sobre a efetividade dos instrumentos jurídicos de ER da UE, iniciando pela regulação estatal, por meio de dados publicados de acordo com a Diretiva 2009/28/CE. Porém, apenas será possível analisar tais dados da nova Diretiva 2001/2018, quando for concluído o ciclo 2020 e tiver início o novo ciclo 2021-2030, atualizado sob o regime do Acordo de Paris. De outro turno, a nova diretiva retirou a obrigatoriedade dos estados membros de terem as suas metas de consumo final de ER e os impactos dessa nova regulação apenas serão aferidas nos anos seguintes, por meio da medição dos dados da EEA.

Em relação à participação social, esta se deu por meio da organização dos cidadãos em cooperativas e, por consequência, pela autorregulação, o que significa que a democracia energética se deu à margem da elaboração de políticas públicas que tenham partido do Parlamento Europeu, mas ainda assim integra a governança de ER da UE. As RECs são importantes para a contenção de crises econômicas e para o aumento da diversidade da produção energética, quebrando assim os monopólios das grandes empresas que exercem forte lobby político.

Além disso, as cooperativas trabalham por um regime de rede de apoios, seja como modelo de negócios, profissionalização ou financiamento. Isto é, optaram por cooperar entre si em vez de competirem no livre mercado, mas ainda assim geram empregos e distribuição de renda. Tal modelo leva aos questionamentos exercidos sobre o Estado como único detentor 
da produção jurídica e das tomadas de decisões que não consideram as medidas plurais vindas da sociedade, do mesmo modo demonstra as limitações do Direito Administrativo Global, por ser um mero instrumento de análise de diferentes regulações, mas sem necessariamente, subvertê-las.

Isto posto, as RECs são instrumentos de fortalecimento de democracia participativa, seja por autorregulação, consulta prévia para as tomadas de decisões e até mesmo mediante ingressos de ações judiciais para obrigar os tomadores de decisões estatais a ouvirem a voz dos cidadãos. Na próxima seção será explicada como a Federação de Cooperativas de ER podem colaborar para com a regulação de ER da UE através do pluralismo jurídico.

\section{A EMERgênCia do PLURALISMo JURídico a PARTIR da dialética ENTRE A FEDERAÇÃO DE COOPERATIVAS DE ENERGIAS RENOVÁVEIS PARA COM A ESTRUTURA REGULATÓRIA DA UE}

Nas duas primeiras partes do artigo, demonstrou-se de que forma se arquitetou a regulação europeia em torno das energias renováveis. A partir disso, utilizou-se como metodologia o Direito Administrativo Global para demonstrar que há uma regulação multinível que abarcam o Direito Internacional Público e o Direito Administrativo Europeu. A regulação multinível insere a União Europeia como um laboratório do Direito Global, isto é, a regulação passa a ser em rede, em vez da tradicional divisão entre direito internacional e direito interno da governança.

Dessa forma, partindo de uma perspectiva fragmentada tanto do modo de produção legislativa do direito internacional, quanto da governança globalizada, o estabelecimento de uma governança global se dá de forma fluída, orgânica, transfronteiriça, ignorando o fato de a produção jurídica ser originalmente local ou internacional. No entanto, o DAG se mostrou limitado para subverter as práticas regulatórias em reverter o poder de influência das empresas sobre as instituições europeias e assim abrir espaço para uma construção radical da democracia.

O DAG, por ser um direito procedimental, utiliza ferramentas de análise, ou seja, serve como controle de políticas públicas, através de práticas de gestão, tais como a accountability e a transparência. Desse modo, através dos dados apresentados acerca da quantidade de consumo final de ER na UE, é verossímil afirmar que houve certa colaboração das Cooperativas de Energias da UE, dado que a quantidade de cooperativas (1.600) não pode 
ser ignorada. Por isso, questiona-se a efetividade da DER/2009 em relação ao alcance da meta de consumo final de ER para o ano de 2020, conforme previsto pela própria diretiva.

De fato, a DER/2009 não prevê a formação das Cooperativas porque a forma de pensar a norma é a de incentivo à competição e concorrência entre os entrantes no mercado, ou seja, a estrutura regulatória foi no sentido de formular uma política de viés com o intuito de criar um novo mercado e exportar esse modelo regulatório por meio de práticas imperialistas eurocêntricas para o sul global.

As cooperativas não são uma novidade contemporânea, pois a forma cooperativa surgiu sempre que houve crises econômicas em grandes proporções, sobretudo na Alemanha. É por isso que utilizaremos como recorte temporal a partir do ano de 2006, quando as RECs começaram a ganhar força, principalmente após a crise neoliberal no ano de 2008. Ressaltese, que as cooperativas precederam a federação REscoop, que foi criada oficialmente em 24/12/2013, através da publicação do seu Estatuto no Diário Oficial da Bélgica (REscoop, 2013).

No entanto, apesar de o Protocolo de Kyoto ter influenciado na criação das cooperativas, estas foram fruto de mobilização dos cidadãos a nível local para construírem esse modelo de auto-gestão e democracia energética. Trata-se de uma associação sem fins lucrativos cujo principal objeto é obter democracia energética, tendo o cidadão como protagonista do negócio, tanto para a produção, como para o consumo. A REscoop possui como o intuito em criar maioria social para o fortalecimento das tomadas de decisões e aprimoramento da democracia, também auxilia na capacitação dos cooperados e fornecem financiamento.

Por isso, a DER/2009 se mostrou insuficiente para responder às necessidades de alcançar as metas estabelecidas. Por consequência, num primeiro momento, a resposta para as lacunas deixadas pela regulação perpassa pela prática e não pela teoria jurídica, através de uma autoconstrução da sociedade (UNGER, 2017, p. 82). A resposta da sociedade civil para com a crise econômica e por consequência em quebrar o monopólio das grandes empresas, isto é, torna-se uma forma de regulação bottom up (de baixo para cima).

No caso das cooperativas, a auto-organização se deu a nível local, ou seja, de forma pulverizada em cada estado membro dentro da municipalidade, e posteriormente se organizaram no nível europeu por meio da Federação. Foi uma resposta dessa chamada autoconstrução da sociedade dando a resposta jurídica na prática pelo que chamamos de 
pluralismo jurídico (UNGER,2017, p. 82). Portanto, deu-se em razão da falta de um aprofundamento da democracia participativa, que foi espontaneamente elaborada com o intuito de reconstruir as estruturas estabelecidas pela UE a fim de diminuir a dependência às crises (UNGER, 2017, p. 82).

Mas de que forma as RECs participam da governança de ER na UE? As diretivas são elaboradas pelo parlamento europeu por uma forma tradicional de regulação que pode ser denominada como uma superestrutura jurídica (PACHUKANIS, 2017). Esta superestrutura busca antecipar a forma que as relações sociais vão ocorrer por meio do poder político a previsão de todas as transações jurídicas de forma pormenorizada:

A lei pode determinar de modo detalhado o que é passível de ser comprado e vendido, pode determinar, ainda, como, em que condições e por quem algo é passível de ser comprado e vendido.

A partir disso, a dogmática jurídica, entre eles o próprio sujeito, são gerados pela norma. Na verdade, claro, a condição prévia fundamental por meio da qual todas essas normas concretas ganham significado consiste na existência da economia-mercantil-monetária. (PACHUKANIS, 2017, p. 103).

Nesta seara, a DER/2009 foi a regulação advinda de uma estrutura política estabelecida por quem detém o domínio econômico. Logo, é formada por uma estrutura regulatória maior pelo Direito Internacional Ambiental (mudanças climáticas) => Seguida de outra estrutura que responde a necessidade de mitigação das mudanças climáticas através das $\mathrm{ER}=>$ metodologicamente as RECs fazem parte de uma auto organização que formam um processo regulatório, que formam um sincretismo entre a estrutura jurídica da UE e auto organização social, fenômeno este que explica a possibilidade do pluralismo jurídico (BARRAUD, 2016).

Esse sincretismo se dá através da dialética que perpassa pela reprodução social relativa à prática realizada pelas RECs como forma de subverter ao forte lobby ocorrido pelo Grupo de Magritte (REscoop, 2015, p. 58). Associado às grandes empresas, tal grupo exerceu pressão junto aos membros da UE, ao Parlamento Europeu e a Comissão Europeia, com o intuito de enfraquecer o modelo de subsídio, bem como limitar o auxílio estatal aos projetos pequenos (REscoop, 2015, p. 58). Isto significa, que houve um movimento reacionário em busca de frear o avanço das cooperativas a partir da influência econômica sobre a superestrutura jurídica, aliando direito, política e economia num movimento uníssono. 
Não obstante, outra tentativa de contra reforma, foi a tentativa de 'hackeamento' da participação social através de grandes empresas realizando pequenos projetos de ER com o motivo de utilizar fórmulas de participação, mas na prática os cidadãos não possuem controle sobre a produção de energia (REscoop, 2015, p. 59). Contudo, A REscoop trabalha no sentido em ter o protagonismo à transição energética por intermédio de pequenos projetos, de forma descentralizada, exclusivamente através de participação cidadã (REscoop, 2015, p. 61).

Assim, o pluralismo jurídico, neste caso, foi a única forma de subverter as instituições estabelecidas a fim de quebrar com a superestrutura jurídica formada pela UE que se trata de uma região de integração econômica, cujo objetivo é atender unicamente à razão neoliberal (DARDOT; LAVAL, 2016) de criar políticas públicas. A questão da razão neoliberal é que ela é em sua essência excludente, ou seja, não dá possibilidades para a descentralização das tomadas de decisões, essencialmente influenciada pelas grandes empresas sob o argumento da capacidade de gerar lucros e por consequência o crescimento econômico.

Seguindo nesse diapasão, não apenas a DER/2009, como toda a forma de pensar a governança europeia são orientadas para superestrutura jurídica estatal em emular as regras de mercado com base na concorrência de forma institucional (DARDOT; LAVAL, 2016, p. 274275). Por isso, as RECs são uma quebra com o padrão jurídico hegemônico mediante da atividade prática objetiva, tendo como protagonistas a participação cidadã (SALOMON, 2006, p. 333). Desse modo, a quebra da hegemonia pode ser explicada como uma quebra da superestrutura jurídica, ancorada na lógica formal do positivismo jurídico, na medida em que o método dialético se apoia no pluralismo jurídico.

Conforme disposto acima, as RECs formam um processo de desestruturação que age no cerne da estrutura regulatória (LEFEBVRE, 1975, p. 36), através de um processo sincrético que forma uma nova estrutura que colabora tanto para com as metas de consumo final de energia mediante fontes renováveis (20\%), quanto para colaborar para com a governança global de ER. Entende-se, portanto, que o Estado não possui o monopólio da produção jurídica, pois uma abordagem científica do direito observa vai além das possibilidades do Estado de Direito (BARRAUD, 2016, p. 39-40).

Desse modo, as RECs atuam essencialmente a partir dos territórios em que os cidadãos se encontram, mas se conectaram em redes mediante a criação de uma Federação de Cooperativas de Energias Renováveis. Tal panorama se trata uma de uma perspectiva de 
autonomia energética que cria uma independência, como uma forma de antídoto tanto para a desindustrialização gerada pela globalização, quanto para as crises econômicas cada vez mais globais.

Destarte, as RECs exercem um papel primordial para direcionar as políticas públicas em ER tendo como finalidade a proteção ambiental, como forma de combate as mudanças climáticas, ao mesmo tempo que dá a possibilidade de ampla participação social. Além disso, a quebra dos monopólios das empresas energéticas que fazem parte do imaginário social em relação a produção energética, demonstra que as formas cooperativas dos meios de produção, pode ser uma forma de mitigar as crises econômicas geradas pelo capital especulativo. Isto é, o a flutuação dos investimentos privados ocorre de forma irresponsável e dissociada da proteção ambiental, bem como aliada a responsabilidade social que essa modalidade produtiva requer.

\section{CONCLUSÃO}

A DER/2009 em seu formato de gestão por metas de resultado, deixa de lado componentes importantes para a sua finalidade que deveria ser a proteção ambiental, no entanto, esta se torna mera alegoria de uma economia verde que não busca democratização energética, na medida em que não busca maior participação social tanto em sua elaboração, quanto em subsidiar elementos de participação social.

Por esses motivos, a governança global em sua fachada por parecer dar um certo frescor ao direito, mas apesar de elaborar com novas formas regulatórias, além de retrair a soberania dos Estados, esta deixa de fora a participação social. Em relação ao combate às mudanças climáticas, este foi cooptado pela ideia de criar ambiente competitivo para com a antiga indústria energética, capitaneada pelo uso do carvão e da energia atômica.

Por conseguinte, as políticas neoliberais, que na prática é operacionalizada pela governança global, tem transformado a gestão pública em planos de metas e objetivos consagradas pela gestão empresarial, no entanto, não consegue integrar a democratização da participação das tomadas de decisões envolvam as partes interessadas.

No entanto, a menor parcela territorial em um governo federativo é o município, pois é nele que se encontram os cidadãos no dia a dia e a partir da pólis que se desenvolveram as cooperativas. Assim, a partir das RECs é verossímil afirmar que tanto a forma de pensar o direito, quanto da elaboração das normas devem ser repensadas, principalmente nas questões 
ambientais, em virtude de envolverem tantas partes interessadas, por perspectivas socioeconômicas diferentes, assim como necessitar de uma análise interdisciplinar.

Assim sendo, as RECs é uma exceção à regra, talvez pela capacidade de mobilização cidadã não significa que pode ser um "padrão" a ser seguido, como uma forma de cooptação da governança global. Na realidade, os modelos de auto-gestão é que devem ser pulverizados em torno do mundo que devem atuar em redes, levando-se em consideração a realidade de cada localidade, território, povos tradicionais, originários. Então, deve-se buscar de uma proteção ambiental que busque a supressão de todas as opressões ocasionadas por decisões catastróficas de políticas públicas que ignoram a participação social, e por isso, a importância do pluralismo jurídico que adiciona o componente prático a teoria do direito.

\section{REFERÊNCIAS}

BARRAUD, B. Théories du Droit et Pluralisme Juridique. Tome II: La théorie syncrétique du droit et la possibilite du plruralisme juridique, Presses Universitaires d'Aix-Marseille, 2016, p. 39-40.

Théories du Droit et Pluralisme Juridique. Tome II: La théorie

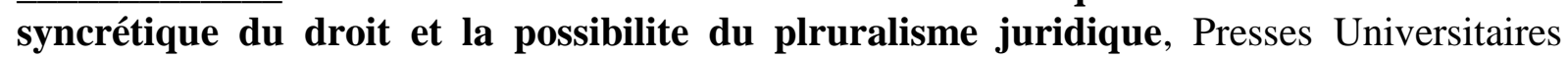
d'Aix-Marseille, 2016, p. 385.

BRADBROOK, A. J. The Development of Renewable Energy Technologies and Energy Efficency Measures through Public International Law. Oxford University Press 2008, p. 109.

CHITI, E.; MATTARELlA, Be. G (eds). Global Administrative Law and EU Administrative Law. Berlin: Springer-Verlag, 2011, p.02.

DARDOT, P.; LAVAL, C. A nova razão do mundo: ensaio sobre a sociedade neoliberal; tradução Mariana Echalar. - 1 ed. - São Paulo: Boitempo, 2016, p. 271-288.

A nova razão do mundo: ensaio sobre a sociedade neoliberal; tradução Mariana Echalar. - 1 ed. - São Paulo: Boitempo, 2016, p. 274.

A nova razão do mundo: ensaio sobre a sociedade neoliberal; tradução Mariana Echalar. - 1 ed. - São Paulo: Boitempo, 2016, p. 274 - 275.

Diretiva 2009/28/CE, considerando (90).

DIZ, J. B. M.; JÚNIOR, A. J. Por uma teoria jurídica da integração regional: a interrelação direito interno, direito internacional público e direito da integração. Revista de Direito Internacional, Brasília, v. 12, n. 2, 2015 p. 138-158. 
EEA - Progress Toward renewable energy source targets at member state an EU - 28 levels. Disponível em: <https://www.eea.europa.eu/data-and-maps/daviz/actual-res-progressindicative-trajectory-7\#tab-chart_4>. Acessado em 05/05/2019.

EEA - Progress Toward renewable energy source targets at member state an EU - 28 levels. Disponível em: <https://www.eea.europa.eu/data-and-maps/daviz/countries-breakdownactual-res-progress-5\#tab-

googlechartid_chart 11_filters $=\% 7 \mathrm{~B} \% 22$ rowFilters $\% 22 \% 3 \mathrm{~A} \% 7 \mathrm{~B} \% 7 \mathrm{D} \% 3 \mathrm{~B} \% 22$ columnFilter s\%22\%3A\%7B\%7D\%3B\%22sortFilter\%22\%3A\%5B\%222020 target\%22\%5D\%7D>.

Acessado em 05/05/2019.

Eurostat - Share of renewables in energy consumption in the EU reached $17 \%$ in 2016. Disponível em: <https://ec.europa.eu/eurostat/documents/2995521/8612324/8-25012018-APEN.pdf/9d28caef-1961-4dd1-a901-af18f121fb2d >. Acessado em 05/05/2019.

FRYDMAN, B. Comment penser le droit global? Working papers du Centre Perelman de Philosophie du Droit, 2012/1.

Comment penser le droit global? Working papers du Centre Perelman de Philosophie du Droit, 2012/1, p. 05.

Comment penser le droit global? Working papers du Centre Perelman de Philosophie du Droit, 2012/1, p. 15.

KELSEN, H. Teoria Pura do Direito. tradução João Baptista Machado. $6^{\text {a }}$ ed. - São Paulo: Martins Fontes, 1998, p. 124-125.

KINGSBURY, B.; CAISINI, L. Global Administrative Law Dimensions of International Organizations Law. Global Administrative Law Series, IILJ Working Paper, 2009/09.

LEAL-ARCAS, R.; MINAS, S. Mapping the International and European Governance of Renewable Energy. Yearbook of European Law Advance Access published october 27, 2016, p. 37.

Mapping the International and European Governance of Renewable Energy. Yearbook of European Law Advance Access published october 27, 2016, p. 39.

Mapping the International and European Governance of Renewable Energy. Yearbook of European Law Advance Access published october 27, 2016, p. 40-41.

LEFEBVRE, H. Lógica formal, Lógica dialética. Rio de Janeiro, Civilização Brasileira, 1975 , p. 76. 
MENDES, Joana. Administrative Law Beyond the State: Participation at the Intersection of Legal Systems. In: CHITI, Edoardo; MATTARELLA, Bernardo Giorgio (ed). Global Administrative Law and EU Administrative Law New York: Springer, 2011, p. 117-120.

NASSER, S. H. Direito Global em Pedaços: Fragmentação, Regimes e Pluralismo. Revista de Direito Internacional, Brasília, v. 12, n. 2, 2015 p. 98-126.

PACHUKANIS, E. B. Teoria Geral do Direito e Marxismo. Tradução Paula Vaz de Almeida; revisão técnica Alysson Leandro Mascaro, Pedro Dagovilo. - 1 ed. - São Paulo: Boitempo, 2017.

PACHUKANIS, E. B. Teoria Geral do Direito e Marxismo. Tradução Paula Vaz de Almeida; revisão técnica Alysson Leandro Mascaro, Pedro Dagovilo. - 1 ed. - São Paulo: Boitempo, 2017, p. 103.

Relatório orientado dos resultados finais do REScoop 20-20-20. Projeto Europa da Energia Inteligente (Intelligent Energy Europe - IEE). Tradução: Alberto Esteves Ferreira Filho (português do Brasil), 2015, p. 55.

Relatório orientado dos resultados finais do REScoop 20-20-20. Projeto Europa da Energia Inteligente (Intelligent Energy Europe - IEE). Tradução: Alberto Esteves Ferreira Filho (português do Brasil), 2015, p. 5.

Relatório orientado dos resultados finais do REScoop 20-20-20. Projeto Europa da Energia Inteligente (Intelligent Energy Europe - IEE). Tradução: Alberto Esteves Ferreira Filho (português do Brasil), 2015, p. 59.

Relatório orientado dos resultados finais do REScoop 20-20-20. Projeto Europa da Energia Inteligente (Intelligent Energy Europe - IEE). Tradução: Alberto Esteves Ferreira Filho (português do Brasil), 2015, p. 61.

REScoop - Legal Statutes. Disponível em: https://uploads.strikinglycdn.com/files/7b5a2f25445d-4cb3-924e-a2622749d3ed/20153012\%20-\%20Statutes\%20-\%20English.pdf $>$. Acessado em 07/05/2019.

REScoop - Who We Are. Disponível em: <https://www.rescoop.eu/federation>. Acessado em 07/05/2019.

What is a REScoop? Disponível em <https://www.rescoop.eu/the-rescoop-model >. Acessado em 07/05/2019.

SALOMON, D. V. A maravilhosa incerteza: ensaio de metodologia dialética sobre a problematização no processo do pensar, pesquisar e criar. $-2^{\mathrm{a}}$ ed. - São Paulo: Martins Fontes, 2006, p. 333.

SLAUGHTER, Anne-Marie. A New World Order. Published by Princeton University Press, 41 William Street, Princeton, New Jersey 08540, 2004. 
UNGER, R. M. O movimento dos estudos críticos do direito: outro tempo, tarefa maior. Tradução de Lucas Fucci Amato - Belo Horizonte: Letramento: Casa do Direito, 2017, p. 82.

UNIÃO EUROPEIA. Tratado Sobre o Funcionamento da União Europeia (versão consolidada). In: Jornal Oficial da União Europeia, C 326/47, de 26 de outubro de 2012. 